\title{
A CYBER-PHYSICAL SYSTEM FOR SMART FIXTURE MONITORING VIA CLAMPING SIMULATION
}

\author{
Zuperl, U. \& Cus, F. \\ University of Maribor, Faculty of Mechanical Engineering, Smetanova 17, 2000 Maribor, Slovenia \\ E-Mail: uros.zuperl@um.si,franc.cus@um.si
}

\begin{abstract}
This paper presents a cyber-physical fixturing system (CPFS) that provides a new way for smart fixture monitoring in milling processes through cloud based simulation and optimization applications. The purpose of the CPFS is to improve the fixture-workpiece stability and thus to prevent deformations of the machined thin-wall workpiece by controlling the simulated clamping and reaction forces at locators. An equilibrium analysis is employed to model and simulate the behaviour of the fixture-workpiece system with respect to the actual cutting tool position. The simulation is incorporated with an optimization routine to minimize the clamping and locating forces. The smart fixture condition monitoring system is developed by connecting the machine tool to the simulation resources in the fixturing platform which performs instant fixture condition monitoring based on signal processing, cutting force signal feature extraction, fixture layout simulations, clamping forces optimization, simulation of clamping/locating forces and process corrective control actions. A prismatic workpiece with slot milling operation is considered to validate the proposed CPFS system. (Received in October 2018, accepted in December 2019. This paper was with the authors 1 month for 1 revision.)
\end{abstract}

Key Words: End Milling, Fixture Condition, Smart Monitoring, On-Line Simulation, Optimization, Clamping/Locating Forces

\section{INTRODUCTION}

The production of complex aero-space parts is known for small series and wide variety of products. The increasing requirements of component performances are a major challenge for the development of milling and clamping techniques. One of the difficulties in machining of such expensive components is thin walls and demanding geometry [1,2]. Large research efforts were devoted to control the quality of the precise machining process $[3,4]$. It is found that deformation of the components during clamping is the main cause of defects $[5,6]$. The deformation of thin-walled products is mainly the result of excessive clamping forces [7]. The clamping forces cause bending of the workpiece leading to the dimensional and shape defects [8]. The greatest deformation occurs when the workpiece is released from the fixture after roughing [9]. The aviation industry reports that the first machining of the classical clamped aero-space parts is less than $50 \%$ successful [5]. Deformation and bending of workpieces during machining can be reduced by optimizing the position and size of the clamping forces [10]. At some point of machining, small clamping forces may be suitable, and on the other point of the tool path, larger forces will be needed. For clamping of thin-walled workpieces, modern fixturing systems have been developed with the clamping force control [11, 12], which is adaptive in relation to the current cutting conditions. In these systems, the position and magnitude of clamping forces are adjusted according to the workpiece geometry and cutting forces. The adaptive fixturing systems are not applicable in the industry due to high implementation costs and limited access to the workpiece [13]. More cost-effective are systems with off-line determination of the clamps position and on-line optimization of clamping force magnitude [11]. Although many studies have been carried out and many adaptive fixturing systems have been performed, only a few systems with the ability to vary the clamping forces and adjust the positions of the locators can be found in industrial environment [14]. Both the open-loop and closed-loop fixturing systems for optimal clamping 
force determination were developed [13]. In calculation, they consider the different cutting tool positions. In an open-loop system, the clamping force is simulated before machining based on the defined tool path. In a closed-loop system, the clamping force is simulated online during machining. On-line process monitoring is very often used to effectively control the quality of machining $[4,15]$. The researchers used force sensors to monitor the cutting and clamping forces [16], sound sensors for tool wear monitoring [17] and accelerometer for vibration monitoring [18]. The sensors for pressure monitoring in clamping cylinders have been also incorporated into the fixtures [11]. Although on-line monitoring is effectively used in machining processes, it is rarely employed for fixture stability and workpiece deformation control $[13,19]$. In machining, several frameworks of cloud based machining monitoring have been designed recently [20, 21]. However, these systems are all in experimental phase. Teti [22] has developed a cloud framework of cutting tool condition monitoring in turning. Tapoglou et al. [20] has developed a cloud-based platform for real time monitoring and for optimal machining parameter selection based on function blocks. Teti et al. [23] examined monitoring achievements in machining. They described four main functions of cognitive smart monitoring systems: sensorial perception and feature extraction, cognitive decision making and action. There is no published research aimed at fixture-workpiece condition monitoring via Internet of Things (IoT) applications. Recently, the emergence of new clamping technologies developed for CNC machine tools is noticeable [24]. These technologies include clamping devices with integrated smart plug-in sensors [25-27] and the ability to communicate with CNC machines and the cloud based applications [28]. IoT with a cloud computing is an efficient environment for sharing data, software and computing capabilities [29]. It also enables the integration of decentralized fixturing systems with machining and monitoring systems. The cloud computing technology is suitable for developing of smart monitoring platforms [30]. It enables us to connect machine tools with clamping systems, measuring systems and monitoring IoT applications via internet networks.

In response to the challenges presented, the study focuses on the development of cyberphysical system for smart fixture monitoring designed for milling of thin-walled workpieces. During fixture monitoring process, the optimal clamping forces and locating forces are simulated and monitored in real time through internet applications based on measured cutting forces and cutting tool position. The developed system that connects the cyber world of computing with machine tool, dynamometer and clamping system is called a cyber-physical fixturing system (CPFS).

The paper is organized as follows. In the first part, a cyber-physical fixturing system (CPFS) for smart fixture condition monitoring is discussed. It describes a structure of the cloud based fixture condition monitoring system. Next four sections describe the IoT applications of the fixturing platform. Subsection 2.5 describes the data acquisition and the communication terminal. Section 3 outlines the simulation and experimental test and presents the obtained results. Section 4 concludes the paper.

\section{CYBER-PHYSICAL FIXTURING SYSTEM}

The goal of this paper is to present a cyber-physical fixturing (CPFS) system for smart fixture condition monitoring via cloud based simulation and optimization applications. The objective of the CPFS is to assure a safe and efficient clamping of thin-walled workpieces during machining by taking into account the pre-processed sensorial data, equilibrium simulations, force simulations, force optimization routines and the corrections of the process parameters. The developed CPFS works as a monitoring system, its structure is shown in Fig. 1. It exploits the advantages of the cloud abilities such as outsourcing signal processing activities (cutting force signal feature extraction), data visualisation, simulations (fixture layout 
analyses), optimization (clamping forces), simulations of the process quantities (locating forces) and corrective control actions (feed rate adjusting). The monitoring structure shown in Fig. 1 is designed on two levels. The lower level includes physical assets (machine tool, dynamometer) and software resources installed in the local data acquisition and communication (DAC) terminal which serves as a communication link between CNC unit, simulation resources and machine tool operator.

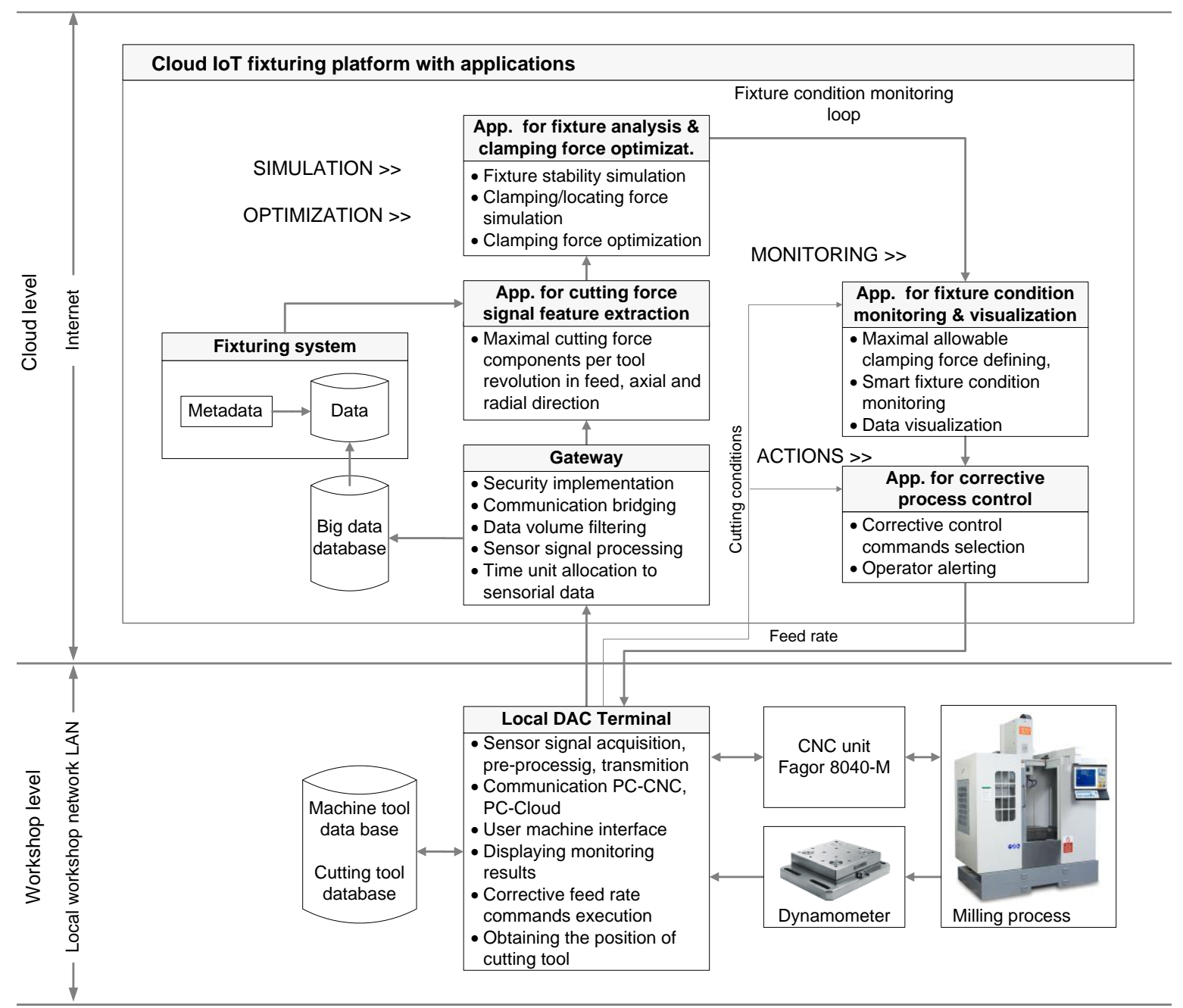

Figure 1: Structure of the smart fixture condition monitoring system.

The physical assets are connected by Local Area Network (LAN) to the analytic resources (data processing, data storing, features extracting, simulations, optimization, monitoring, data visualization, process parameters correction) on the cloud level. The two level system acquires the signals from the dynamometer and applies them for fixture condition monitoring.

The computing resources in the cloud are defined as cloud based fixturing platform. The platform is realized with one communication element and four applications.

The sensor signal pre-processing is performed on the machine tool level. The sensor data are collected, reduced, transformed into data packages and transported to the IoT gateway over the LAN. The communication element implements a part of edge computing activities i.e.: security, communication bridging, collecting the sensor data, storing data and filtering data. This element, designated as an IoT gateway, collects the pre-processed data and reduces it to the amount necessary for the monitoring process.

The application for cutting force signal feature extraction is then employed to capture applicable information for fixture layout analyses and clamping force optimization. The 
second application, application for fixture analysis and clamping force optimization simulates the optimum magnitudes of clamping and locating forces for all fixture layout cases during machining. The third application ensures fixture condition monitoring and provides human machine interface with data visualization. The fourth application performs the feed rates adjusting and operator alerting in order to ensure fixture stability and to prevent the workpiece deformations. The feed rate adjusting commands are sent back to the lower local DAC terminal which executes the control actions in connection with the Fagor CNC control unit.

The fifteen spatially dislocated steps are performed to execute the fixture condition monitoring.

>>> Data acquisition and communication terminal-Local DAC terminal >>>

1. Cutting force signal acquisition, pre-processing and transmission to the cloud level.

2. Establishing a communication link to the gateway.

>>> Cloud level - IoT fixturing platform >>> >

3. Security implementation, data filtering, communication bridging.

4. Cutting force signal feature extraction and storing in the IoT platform gateway.

5. Cutting tool positions acquiring.

6. Fixture layout simulation, clamping force optimization, reaction forces simulation.

7. Defining the maximal allowable clamping forces.

8. Smart fixture condition monitoring, the corrective control actions selection.

9. Visualization of the results of computing, analysis and monitoring.

10. Monitoring results in graphical form are projected back to the local DAC terminal.

11. The feed rate corrective commands are sent back to the DAC terminal. >>> Data acquisition and communication terminal - Local DAC terminal >>>

12. Executing of the control commands; constructing and sending a communication telegram with the feed rate corrective command to the $\mathrm{CNC}$ controller.

13. Communication with CNC controller via DNC protocol.

14. Displaying monitoring results in graphical form.

15. Steps 1 to 14 are repeated until the termination of machining.

\subsection{Application for cutting force signal feature extraction}

In this IoT application, the maximal cutting forces per cutting tool revolution providing adequate information for the fixture condition monitoring are extracted from the preprocessed sensorial data. The application is based on the employment of the piezoelectric triaxial force sensor mounted on the machining table. It acquires the components of maximal cutting force per tool revolution in feed, axial and radial directions.

The main algorithm for data acquisition and sensor signal processing is designed in LabVIEW software installed on local DAC terminal. The three inputs of the measuring card are reserved for cutting force components and one for the CNC coordinates of cutting tool position. The obtained cutting force components from all three channels are combined and transferred via gateway to the application for cutting force signal feature extraction.

In this application, the transferred data is separated by a loop into a single channel, and then the maximum measured value of the cutting force per cutting tool revolution is found for each channel. The maximal values of cutting force components are transferred forward to the application for fixture analysis and clamping force optimization. Data transfer between the applications is accomplished through system variables $F f(t)[\mathrm{N}], F a(t)[\mathrm{N}], F t(t)[\mathrm{N}]$ and time $t$. The system variables are also linked to the indicators for numerical and graphical display on the IoT application for fixture condition monitoring and data visualization.

In this IoT application, the statistical features from the cutting force signals were extracted in the time domain. However, some of the distinctive features, which are not visible in the time domain, could be only revealed using the analysis in the frequency domain. To overcome 
this limitation, the chatter vibration analysis in frequency domain was performed before the experiment in order to find the cutting conditions which do not cause vibrations. The selection of proper cutting conditions to avoid vibrations is essential to accurately perform the experiment. If vibrations occur, the $R a$ increases by up to $40 \%$ and the maximal cutting forces increase drastically. Based on the increased cutting forces, the system recalculates the required optimal clamping forces and corresponding locating forces in real time. The CPFS responds to the occurrence of vibrations with feed rate correction only if the maximum allowable clamping forces are exceeded. When this condition is attained, the CPFS corrects the feed rates in order to ensure the fixture stability. Reducing the feed rates reduces the cutting forces and thus suppresses the vibrations. In order to check the frequencies classified as vibrations, the measured dynamic cutting force data were transformed into the frequency domain using standard Fast Fourier transform (FFT) algorithm. The FFT analysis revealed that the prevailing peak frequency occurred at the tooth passing frequency followed by its harmonics. Furthermore, no significant vibrations frequencies were observed in the frequency spectrum for the planned range of cutting conditions.

\subsection{Application for fixture analysis and clamping force optimization}

This IoT application is designed for fixture layout analyses and optimization since it can online simulate the optimum values of clamping and locating (reaction) forces for different fixture layout cases. The purpose of this simulation/optimization application is to improve the fixture layout and thus to increase the geometrical accuracy of the machined thin-wall workpiece. The proposed application employs the rigid body equilibrium analysis method to model the condition of fixture-workpiece system. This method is simple and efficient to analyse the condition of the fixture-workpiece system with respect to fixture layout, clamping forces, cutting forces and cutting tool position. It considers modelling of the reaction forces at locators. The reaction forces are modelled based on static clamping forces and machining forces, varying with respect to the cutting tool position. The fixture-workpiece model is further used to improve the workpiece dimensional quality by minimizing the reaction and clamping forces. Therefore, the equilibrium analysis is incorporated with a simple optimization routine. The application in simulations considers the properties of the workpiece, the friction between fixture elements and workpiece, the locating elements positions and the clamping forces positions and magnitudes. It is designed for analysing the modular fixtures intended for clamping of prismatic workpieces. The 3-2-1 fixture configuration principle is used to locate the workpiece as shown in Fig. 2. The locators act on the workpiece with six locating forces $\left(F_{1}-F_{6}\right)$. The reaction forces on the locating elements must be always more than 0 , otherwise the workpiece is not in equilibrium. Three clamps, modelled as point forces $C_{1}, C_{2}$, and $C_{3}$, are used to clamp the workpiece against the locators. They act towards the locators on which the workpiece is located. They must ensure the workpiece equilibrium and prevent elastic and plastic deformation of the workpiece surface. The resulting friction forces in contact points between the fixture elements and workpiece is labelled with $f_{i}$. The positions of locators, clamps and cutting tool are represented by vectors $r_{i}(i=1, \ldots, 9)$. The components of cutting force are assumed as point forces acting in the feed $\left(F_{f}\right)$, axial $\left(F_{a}\right)$ and tangential $\left(F_{t}\right)$ directions as shown in Fig. 2. The cutting force coordinates are acquired using DNC function via local DAC-terminal during machining and used to form the position vector in equilibrium analysis. The governing equations are developed by applying static equilibrium conditions in order to represent the fixture-workpiece system and thus to predict the reaction forces at locators for a particular machining simulation and fixture layout case.

The equilibrium equations are written in the matrix form (see Eq. (1)) and inverse matrix method is used to solve the equation. The geometrical matrix $[A]$ consists of the coefficients of the left side parameters of the governing equations. The vector of external forces $\left[w_{e}\right]$ 
contains the constants of the right side of governing equations. The reaction forces on locators $\left(F_{1}\right.$ to $F_{6}$ ) form a vector of locating forces $[F]$. Vector $[F]$ is determined by solving the matrix equation.

$$
[A] \cdot[F]=-\left[w_{e}\right]
$$

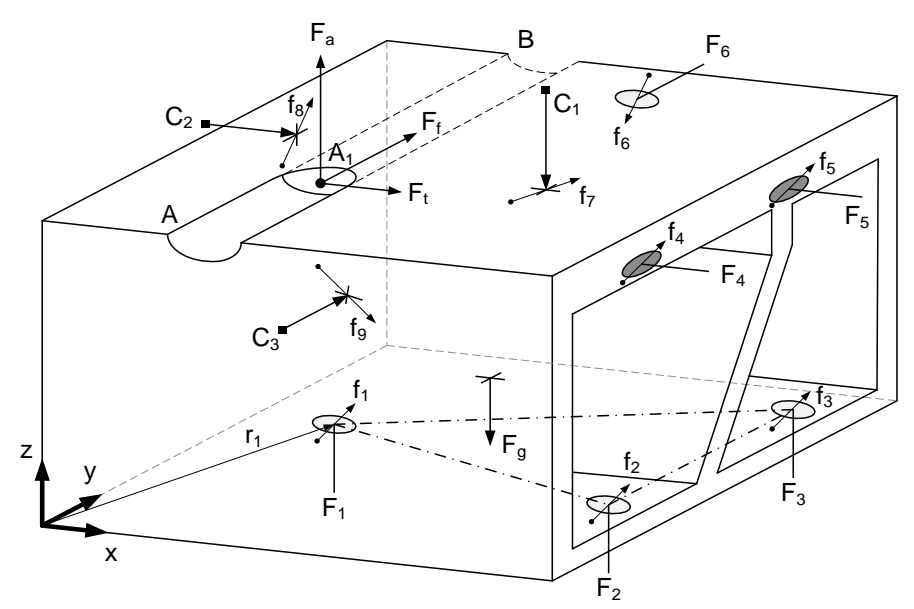

Positions of locators:
$F_{1}(40,140,0)$
$F_{2}(160,75,0)$
$F_{3}(160,230,0)$
$F_{4}(180,105,80)$
$F_{5}(180,190,80)$
$F_{6}(100,255,80)$
Positions of clamps:
$C_{1}(120,140,100)$
$C_{2}(0,140,80)$
$C_{3}(100,0,80)$
Position of cutting force-
point $A 1:$
$A_{1}(75,130,96)$
Position of gravity force:
$F_{g}(97,135,48)$
Resulting friction forces in
contact points $(N)$ :
$f_{i},(i=1-9)$

Figure 2: Simulation origin; fixture- workpiece system configuration with the cutting force.

The described workpiece-fixture model was proposed for the CPFS due to its simplicity and low calculation requirements which are necessary for on-line application. The model was easily converted into the cloud application. The same model has been also employed by other researches with favourable results [31]. However, the applied rigid body equilibrium analysis method to model the behaviour of the workpiece-fixture system has one significant weakness. The method is statistically indeterminate; as a result the workpiece displacements cannot be determined uniquely [31]. This limitation can be overcome by considering the elastic deformations at the contact between the fixture and the workpiece [31]. However, to build and to integrate the dynamic simulation model that incorporates the overall interaction between the workpiece and clamping components into the cloud application is difficult and time consuming and requires extensive effort.

Eq. (1) is also used in the clamping force optimization process. The optimization process is required to minimize the reaction forces at the locators during simulation and machining test. The determination process of optimal clamping forces is carried out by using the iteration method. The iteration method solves Eq. (1) by incrementally increasing all three clamping forces from zero to the starting optimal value, where all the $F_{i}$ are non-negative. The calculated starting optimal value is then assigned to the $C_{1}$. The $C_{2}$ and $C_{3}$ are incrementally increasing from zero to the value, where all the locating forces are non-negative. The above process is then repeated for the $C_{2}$ and for $C_{3}$. The simulated clamping and locating forces are the input to the application for fixture condition monitoring and data visualization and the application for corrective process action. The values of simulated forces are associated with the display indicator on the human machine interface.

\subsection{Application for fixture condition monitoring and visualization}

This application is used as a control panel on the IoT fixturing platform to monitor the fixture condition and to visualize the simulation results with a large amount of captured data from the cutting force sensor. The control panel shows the measured cutting force components, the simulated clamping forces with corresponding locating forces, the corrective control actions and errors acquiring during executing of the software.

The graphical human interface of the developed application is developed in LabVIEW (Fig. 3). 


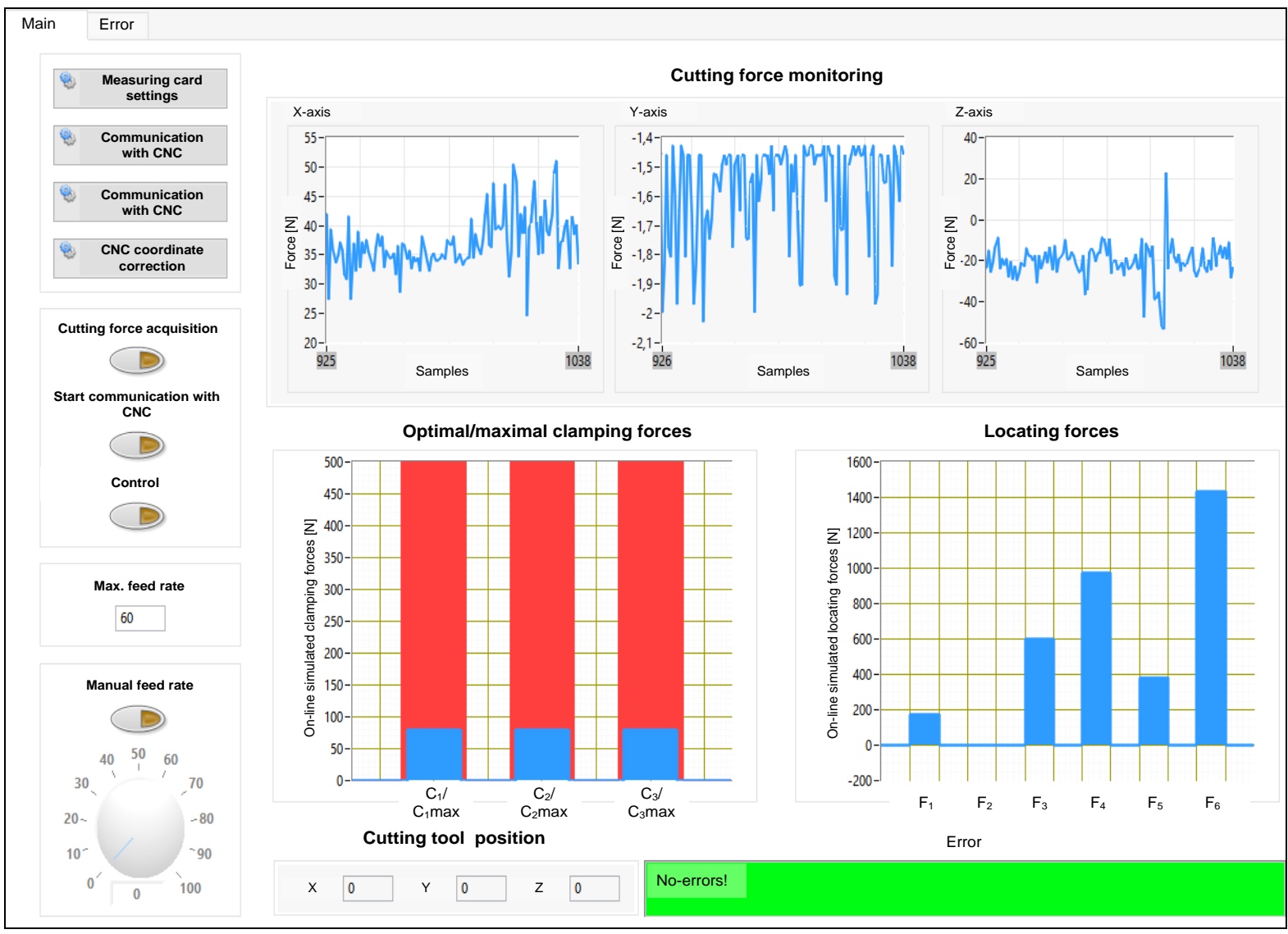

Figure 3: Control panel for smart fixture condition monitoring with on-line simulated clamping / locating forces.

It allows fast and simple adjusting of connected equipment. The interface is divided into two parts, the part with controls and the part with indicators. The first part contains controls to set the software parameters. There are four buttons for setting the measuring card, the communication with the CNC machine, the algorithms for simulating the optimal clamping forces and for correcting the cutting tool coordinates (Fig. 3). The Control button provides the code for simulating the optimal clamping forces and determining the corrective machining process actions. The indicator part of the control panel graphically and numerically presents the measured cutting forces, the simulated optimal clamping forces with maximal allowable clamping forces, corresponding simulated locating forces, current coordinates of the cutting tool and errors. The indicators for the simulated and maximum permissible clamping forces overlap, in order to make it easier to determine the differences. The indicator of locating forces in Fig. 3 indicates, that the workpiece is safely clamped at the current cutting tool position and that the critical element of the fixture is the locator \# 2. When error occurs while running the software, the background of the indicator is changed from green to red.

\subsection{Application for corrective process control}

A cloud application is built as a corrective control system that continuously monitors the simulated optimal clamping forces and if necessary, adjusts the feed rates. For each cutting tool revolution, the measured cutting forces are used to simulate the optimal clamping forces, and these values are compared to the $C_{i} \max$. If the maximal allowable clamping forces $\left(C_{1} \max\right.$ or $C_{2} \max$ or $\left.C_{3} \max \right)$ are exceeded, the control action is carried out within $5 \mathrm{~ms}$ after the occurrence. When this condition is attained, the corrective control action is transferred to the local DAC-terminal, which sends the DNC command to the CNC controller to adjust the 
milling process. Simultaneously, the alarm is sent to the control panel for fixture condition monitoring and clamping force control, where the operator can visualize a warning with the graphical indication that the $C_{i} \max$ is exceeded. This process is repeated till the end of simulation and/or machining test. The IoT application corrects the feed rates in order to ensure the fixture stability. Reducing the feed rate reduces the cutting forces and thus reduces the necessary optimal clamping forces.

The correction process starts with the value of the feed rate override percentage $f=100 \%$, after that this value decreases incrementally, until $C_{i}$ are smaller than limited clamping force $\left(C_{i}\right.$ limit; $\left.i=1,2,3\right) . C_{i}$ limit is set to $90 \%$ of the $C_{i}$ max. If $C_{i}$ is smaller than $C_{i}$ limit, the feed rate override percentage increases incrementally back to the initial $100 \%$.

\subsection{Data acquisition and communication terminal}

The local PC is used as a data acquisition and communication terminal. The main purpose of the local DAC terminal is to pre-process the signals from dynamometer, to transmit the sensor signals to the cloud fixture condition monitoring platform, to communicate with CNC controller and to display the control panel of the CPFS. In signal pre-processing, the signals from the piezoelectric tri-axial dynamometer (Kistler 9257) are conditioned through dual mode charge amplifier (Type 5001) with in-built low pass filter of $1 \mathrm{kHz}$ cut-off frequency. Then, the signals are outputted to a NI data acquisition board. The main algorithm for data acquisition and sensor signal pre-processing consists of five functions designed in LabVIEW software. The pre-processed signals are sent based on the hypertext transfer protocol to the cloud fixture condition monitoring platform in order to execute fixture analysis, clamping/locating force simulation, clamping force optimization and fixture monitoring. The local DAC terminal establishes a communication link to the gateway on the cloud platform and with the machine tool CNC controller. During smart fixture condition monitoring, the monitoring results in graphical form are projected back to the local DAC terminal. If the process adjusting actions are adopted, the feed rate corrective commands are sent back to the terminal. The DAC terminal accepts the control commands, constructs and sends a communication telegram with the adequate feed rate corrective command directly to the $\mathrm{CNC}$ controller. The automatically executed corrective feed rate action is confirmed and visualized on the control panel. The algorithm for establishing communication with the CNC controller is performed in an independent loop and is not limited by the speed and availability of data of other algorithms. To ensure quick and appropriate response to different events, the algorithm is built as a state machine with 4 states: Start, Stop, Master device and Slave device. In accordance with the DNC protocol, the fixture condition monitoring platform (master) sends a request to the controller (slave) to adjust the process parameter and request for obtaining the CNC coordinates of the cutting tool. After that, the CNC controller responds accordingly. The process corrective control action is performed using the DNCFRO variable.

\section{SIMULATION AND EXPERIMENTAL DEMONSTRATION}

The effectiveness of the proposed cloud based fixture condition monitoring system is verified by considering a slot milling on a prismatic workpiece. The workpiece is $178 \mathrm{~mm} \times 254 \mathrm{~mm} \times$ $100 \mathrm{~mm}$ pre-machined thin-walled deformable profile made from CK-45 steel. A slot is made for the size of $16 \mathrm{~mm} \times 254 \mathrm{~mm} \times 4 \mathrm{~mm}$ with $16 \mathrm{~mm}$-diameter 2 -flute cutter. The detail of the workpiece is presented in Fig. 2. The length of the tool path $(254 \mathrm{~mm})$ is divided due to presentation clarity into thirty equal lengths. The machining process is carried out from point A to point B with the following initial machining parameters: cutting speed is $50 \mathrm{~m} / \mathrm{min}$, feed rate $\left(f_{z}\right)$ is $0.5 \mathrm{~mm} /$ tooth and cutting depth is $4 \mathrm{~mm}$. 
A preliminary simulation experiment is performed to analyse the stability of the workpiece-fixture system for all thirty sections of the tool path before the start of the machining experiment.

The simulation experiment is performed to predict the required starting optimal clamping forces and corresponding reaction forces on the locators with the consideration of cutting forces corresponding to the initial machining parameters. The maximal cutting force calculated according to the cutting force model of end milling [16] for section A-B is taken as $\left[F_{a}, F_{f}, F_{t}\right]=[450 \mathrm{~N}, 315 \mathrm{~N}, 810 \mathrm{~N}]$.

In order to simulate the optimal clamping force and corresponding locating forces for the tool path point A1, the tool position, the starting positions of clamping/locating elements, the friction coefficient $(\mu=0.3)$ and the workpiece weight $\left(F_{g}=47 \mathrm{~N}\right)$ are entered in the application for fixture condition monitoring and data visualization. The static coefficient of friction was adopted from the work of Deiab and Elbestawi [32], where the results of an experimental investigation of the workpiece/fixture contact characteristics are presented. As shown in Fig. 2, a 3-2-1 locating principle is employed and 3 clamping elements are considered. Using the application for fixture analysis and clamping force optimization, the optimal clamping forces with corresponding locating forces, which are all greater than 0 , are obtained. They are presented in Fig. 4. The obtained set of optimal clamping forces $\left[C_{1}, C_{2}, C_{3}\right]=[410 \mathrm{~N}, 220 \mathrm{~N}, 0 \mathrm{~N}]$ ensures that the workpiece will not slide from the locators during the cutting at the position A1. When the cutting tool is at position A1, critical element of the fixture is the locating element $F_{1}$.

The simulations are repeated for all other tool path points which are determined at intervals of $5 \mathrm{~mm}$ along the tool path A-B. The second, more conservative set of clamping forces $\left[C_{1}, C_{2}, C_{3}\right]=[431 \mathrm{~N}, 431 \mathrm{~N}, 431 \mathrm{~N}]$ shown in Fig. 4 is selected as starting fixed clamping forces set applied during the machining experiment. The workpiece will be safely clamped when the clamping forces are $431 \mathrm{~N}$. The maximal allowable clamping forces $\left(C_{1} \max , C_{2} \max , C_{3} \max \right)$ are set to $431 \mathrm{~N}$. The $C_{i}$ limit is set to $387 \mathrm{~N}$.

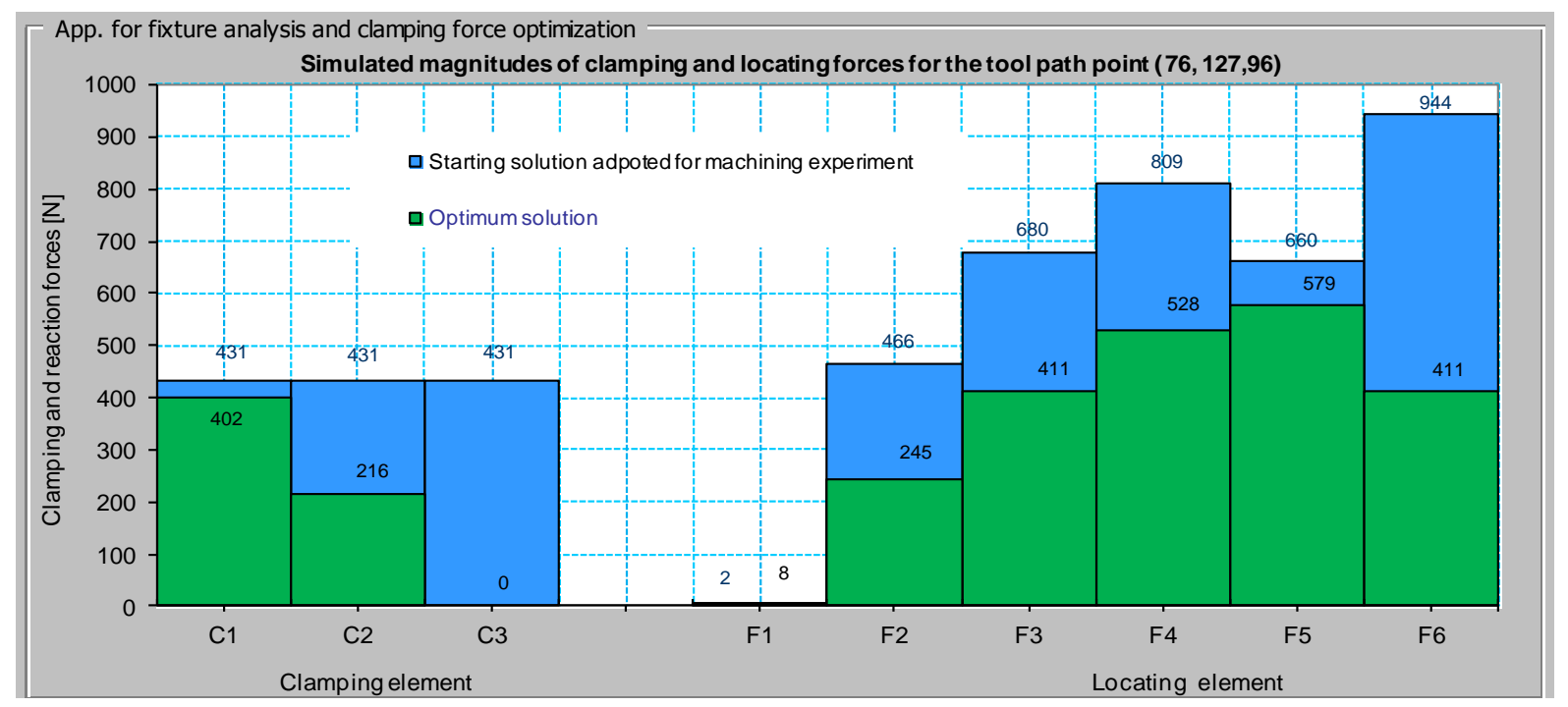

Figure 4: The simulated optimal clamping forces with corresponding reaction forces.

In the milling experiment, the optimal clamping forces are simulated in real time based on the cutting tool position and measured cutting forces. The reaction forces on the six locators during milling experiment are shown in Fig. 5 a. The magnitude of reaction forces $F_{1}$ and $F_{3}$ decreases as the tool path increases. At the beginning of the experiment, the $F_{1}$ and $F_{3}$ are located away from the position of cutting forces. Hence, the magnitude of locating forces decreases as the position of cutting forces approaches close to them. From the tool path point 
$(76,80,96)$ forward, the magnitude of locating force $F_{2}$ increases to the maximum. This is due to the cutting forces position which is close to the $F_{2}$ position at the beginning and moves away as machining progresses. The locating force $F_{6}$ remains constant during machining since it provides opposite reaction to $F_{f}$ cutting force component.

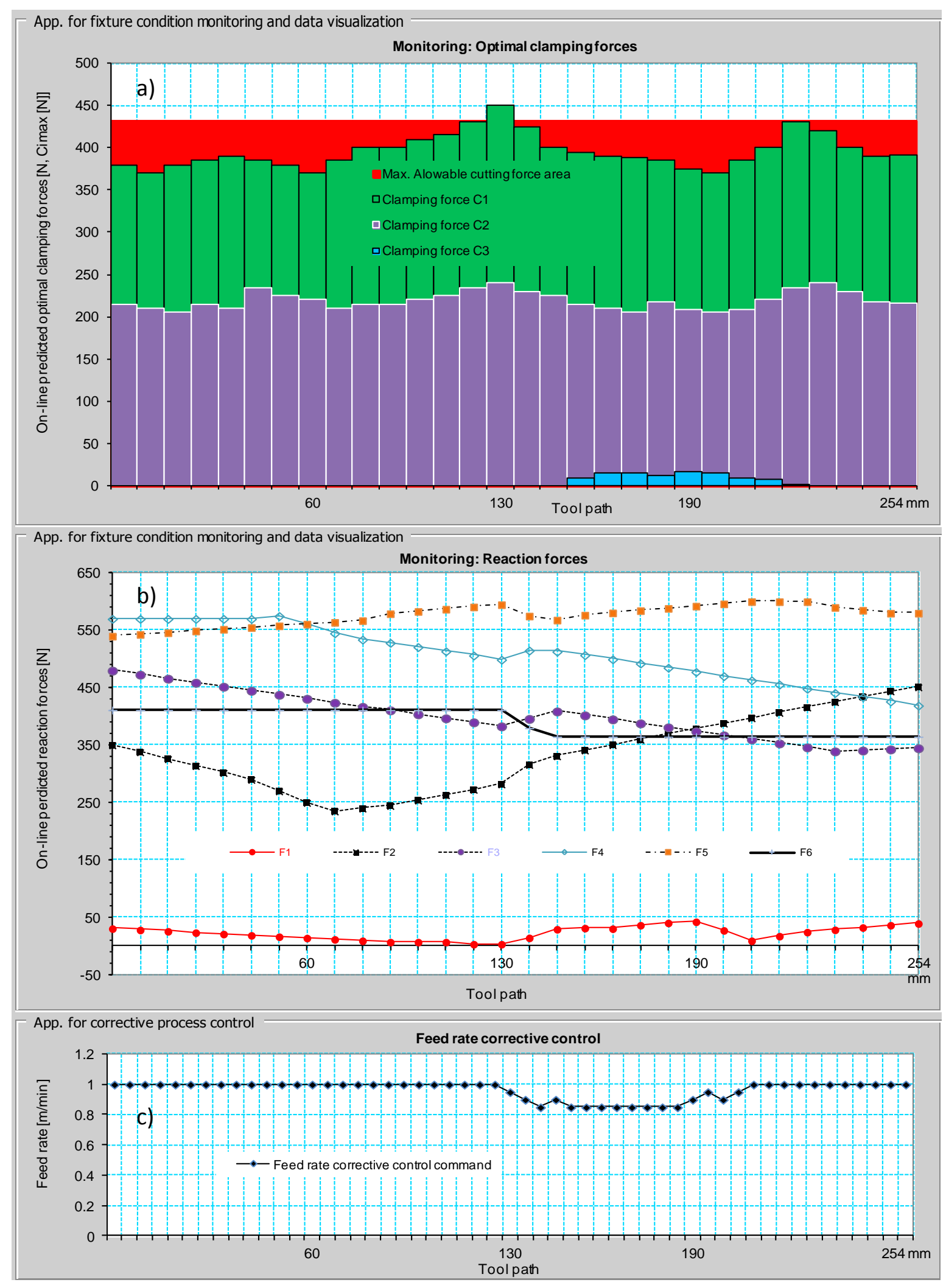

Figure 5: Monitoring results of simulated optimal clamping force distribution, reaction force distribution and feed rate corrective control command responses for the whole tool path A-B. 
When, at the tool path position $(76,130,96)$, the simulated force $F_{1}$ is close to zero, the $C_{1}$ has to increase above the $C_{i} \max$ (see Fig. $5 \mathrm{~b}$ ) in order to maintain the workpiece in equilibrium. Therefore, the feed rate drops down to $0.8 \mathrm{~m} / \mathrm{min}$ in order to maintain the $C_{1}$ below the maximal allowable clamping force $\left(C_{i} \max =431 \mathrm{~N}\right)$. At this point, there is a significant jump of locating forces $F_{1}, F_{2}, F_{3}, F_{4}$ and noticeable drop of locating forces $F_{5}$ and $F_{6}$. The $C_{3}$ increases up to $20 \mathrm{~N}$. The response of feed rate during experiment is shown in Fig. 5 c. The response of optimal clamping forces and $C_{i} \max$ is shown in Fig. $5 \mathrm{~b}$. When, at the tool path position $(76,190,96)$, the $C_{1}$ decreases below the $C_{i}$ limit (see Fig. 5 b), the feed rate incrementally returns back to initial $1 \mathrm{~m} / \mathrm{min}$. It is clear that the $C_{1}$ constraints the workpiece movement in the upward direction which is caused by the $F_{a}$. Similarly, the $C_{2}$ has to restrict the effect of $F_{t}$. It is clear that the $C_{1}$ constraints the workpiece movement in the upward direction which is caused by the $F_{a}$. Similarly, the $C_{2}$ has to restrict the effect of $F_{t}$. The clamping forces $C_{3}$ is less significant as it acts against the direction of the $F_{f}$.

Due to the adjustment of feed rate from 0.8 and back to $1 \mathrm{~m} / \mathrm{min}$, the $R a$ increased from $1.91 \mu \mathrm{m}$ to $2.22 \mu \mathrm{m}$. The results of the experiment showed that while adjusting the $f$, the $R a$ increased in the same way as the maximal resultant cutting force. Therefore, the $R a$ average has the same trend as the measured maximal cutting force at the identical machining parameter. The manufactured surface had constant, curved marks that were denser in the area of feed rate adjustment. In addition, the feed rate adjustment has the largest impact on cutting force and consequently on surface roughness.

The simulation and machining experiment demonstrated that the optimal clamping forces can be controlled by adjusting the feed rate.

\section{CONCLUSION}

In this study, a cyber-physical fixturing (CPFS) system was successfully implemented to monitor the condition of the fixture via cloud based simulation and optimization applications. The purpose of the CPFS is to improve the fixture layout and thus to increase the geometrical accuracy of the machined workpiece by optimizing the simulated clamping forces and minimizing the simulated reaction forces on locators. The CPFS is developed as a two level monitoring system. The lower, workshop level includes physical assets and software resources installed in the local DAC terminal. The physical assets are connected by LAN to the cloud based fixturing platform, where simulation resources are situated. The platform exploits the advantages of the cloud abilities such as outsourcing signal processing activities (cutting force signal feature extraction), data visualisation (monitoring panel), simulations (fixture layout analyses), optimization (clamping forces), process quantities simulation (locating forces) and corrective control actions (feed rate adjusting). The software applications of the fixturing platform enable immediate fixture layout simulation based on the cutting tool position and measured cutting forces.

In simulation and milling experiment, the optimal clamping forces and locating forces are simulated and monitored in real time through internet applications based on measured cutting forces and cutting tool position. Variable clamping force control has been implemented in CPFS by incrementally adapting of feed rate. The simulation-cutting experiment demonstrated that the optimal clamping forces can be controlled by adjusting the feed rate. The proposed cloud based monitoring system is proven to be flexible in improving part dimensional quality through minimizing of reaction forces on the locators.

In the future, the proposed workpiece-fixture simulation model will be integrated with a Particle Swarm Optimization (PSO) routine in order to obtain a uniform distribution of reaction forces during machining by optimizing the positions of the supporting elements and clamping forces. Furthermore, some limitations of the proposed workpiece-fixture model 
based on rigid body equilibrium analysis may be overcome by considering the elasticity of the workpiece-fixture system. Therefore, future activities will be directed to build a dynamic simulation model that will include the overall interactions between the workpiece and the fixture and to perform the optimisation of the workpiece-fixture system in the presence of dynamic forces. The special interest of future activities will be to integrate a force-controlled clamping element with corresponding IoT control application into the CPFS with the intention to further minimize the workpiece deformation.

\section{REFERENCES}

[1] Aoyama, T.; Kakinuma, Y. (2005). Development of fixture devices for thin and compliant workpieces, CIRP Annals, Vol. 54, No. 1, 325-328, doi:10.1016/S0007-8506(07)60114-0

[2] Yang, L.; Zheng, M. L. (2017). Simulation and analysis of ball-end milling of panel moulds based on Deform 3D, International Journal of Simulation Modelling, Vol. 16, No. 2, 343-356, doi:10.2507/IJSIMM16(2)CO9

[3] Gao, R. X.; Tang, X.; Gordon, G.; Kazmer, D. O. (2014). Online product quality monitoring through in-process measurement, CIRP Annals, Vol. 63, No. 1, 493-496, doi:10.1016/ j.cirp.2014.03.041

[4] Möhring, H.-C.; Litwinski, K. M.; Gümmer, O. (2010). Process monitoring with sensory machine tool components, CIRP Annals, Vol. 59, No. 1, 383-386, doi:10.1016/j.cirp.2010.03.087

[5] Li, Y.; Liu, C.; Hao, X.; Gao, J. X.; Maropoulos, P. G. (2015). Responsive fixture design using dynamic product inspection and monitoring technologies for the precision machining of largescale aerospace parts, CIRP Annals, Vol. 64, No. 1, 173-176, doi:10.1016/j.cirp.2015.04.025

[6] Oman, S.; Nagode, M. (2017). Bolted connection of an end-plate cantilever beam: the distribution of operating force, Strojniski vestnik - Journal of Mechanical Engineering, Vol. 63, No. 11, 617-627, doi:10.5545/sv-jme.2017.4638

[7] Ramesh, R.; Mannan, M. A.; Poo, A. N. (2000). Error compensation in machine tools - a review: Part I: geometric, cutting-force induced and fixture-dependent errors, International Journal of Machine Tools and Manufacture, Vol. 40, No. 9, 1235-1256, doi:10.1016/S08906955(00)00009-2

[8] Raghu, A.; Melkote, S. N. (2004). Analysis of the effects of fixture clamping sequence on part location errors, International Journal of Machine Tools and Manufacture, Vol. 44, No. 4, 373382, doi:10.1016/j.ijmachtools.2003.10.015

[9] Borojević, S.; Lukić, D.; Milošević, M.; Vukman, J.; Kramar, D. (2018). Optimization of process parameters for machining of Al 7075 thin-walled structures, Advances in Production Engineering \& Management, Vol. 13, No. 2, 125-135, doi:10.14743/apem2018.2.278

[10] Chen, W.; Ni, L.; Xue, J. (2008). Deformation control through fixture layout design and clamping force optimization, The International Journal of Advanced Manufacturing Technology, Vol. 38, No. 9-10, 860-867, doi:10.1007/s00170-007-1153-2

[11] Mannan, M. A.; Sollie, J. P. (1997). A force-controlled clamping element for intelligent fixturing, CIRP Annals, Vol. 46, No. 1, 265-268, doi:10.1016/S0007-8506(07)60822-1

[12] Župerl, U.; Čuš, F.; Vukelić, Đ. (2011). Variable clamping force control for an inteligent fixturing, Journal of Production Engineering, Vol. 14, No. 1, 19-22

[13] Bakker, O. J.; Papastathis, T. N.; Popov, A. A.; Ratchev, S. M. (2012). Active fixturing: literature review and future research directions, International Journal of Production Research, Vol. 51, No. 11, 3171-3190, doi: 10.1080/00207543.2012.695893

[14] Wan, X.-J.; Zhang, Y. (2013). A novel approach to fixture layout optimization on maximizing dynamic machinability, International Journal of Machine Tools and Manufacture, Vol. 70, 3244, doi:10.1016/j.ijmachtools.2013.03.007

[15] Basar, G.; Akin, H. K.; Kahraman, F.; Fedai, Y. (2018). Modeling and optimization of face milling process parameters for AISI 4140 steel, Technical Journal, Vol. 12, No. 1, 5-10, doi: $10.31803 /$ tg-20180201124648

[16] Bakker, O. J.; Popov, A.; Ratchev, S. (2008). Control of a workpiece holder with piezo-electricmechanical actuation, Journal of Machine Engineering, Vol. 8, No. 3, 17-28 
[17] Rao, K. V.; Murthy, B. S. N.; Rao, N. M. (2013). Cutting tool condition monitoring by analyzing surface roughness, work piece vibration and volume of metal removed for AISI 1040 steel in boring, Measurement, Vol. 46, No. 10, 4075-4084, doi:10.1016/j.measurement.2013.07.021

[18] Min, S.; Lidde, J.; Raue, N.; Dornfeld, D. (2011). Acoustic emission based tool contact detection for ultra-precision machining, CIRP Annals, Vol. 60, No. 1, 141-144, doi:10.1016/ j.cirp.2011.03.079

[19] Bakker, O. J.; Popov, A. A.; Ratchev, S. M. (2009). Model-based control of an advanced actuated part-fixture system, Proceedings of the ASME 2009 International Manufacturing Science and Engineering Conference, 381-393, doi:10.1115/MSEC2009-84175

[20] Tapoglou, N.; Mehnen, J.; Vlachou, A.; Doukas, M.; Milas, N.; Mourtzis, D. (2015). Cloudbased platform for optimal machining parameter selection based on function blocks and real-time monitoring, Journal of Manufacturing Science and Engineering, Vol. 137, No. 4, Paper 040909, 11 pages, doi:10.1115/1.4029806

[21] Kim, S.-J. (2016). Integration of pre-simulation and sensorless monitoring for smart mould machining, International Journal of Simulation Modelling, Vol. 15, No. 4, 623-636, doi:10.2507/IJSIMM15(4)4.354

[22] Teti, R. (2015). Advanced IT methods of signal processing and decision making for zero defect manufacturing in machining, Procedia CIRP, Vol. 28, 3-15, doi:10.1016/j.procir.2015.04.003

[23] Teti, R.; Jemielniak, K.; O’Donnell, G.; Dornfeld, D. (2010). Advanced monitoring of machining operations, CIRP Annals, Vol. 59, No. 2, 717-739, doi:10.1016/j.cirp.2010.05.010

[24] Gotlih, J.; Brezocnik, M.; Balic, J.; Karner, T.; Razborsek, B.; Gotlih, K. (2017). Determination of accuracy contour and optimization of workpiece positioning for robot milling, Advances in Production Engineering \& Management, Vol. 12, No. 3, 233-244, doi:10.14743/apem2017.3.254

[25] Möhring, H.-C.; Wiederkehr, P.; Lerez, C.; Schmitz, H.; Goldau, H.; Czichy, C. (2016). Sensor integrated CFRP structures for intelligent fixtures, Procedia Technology, Vol. 26, 120-128, doi:10.1016/j.protcy.2016.08.017

[26] Matejic, M.; Tadic, B.; Lazarevic, M.; Misic, M.; Vukelic, D. (2018). Modelling and simulation of a novel modular fixture for a flexible manufacturing system, International Journal of Simulation Modelling, Vol. 17, No. 1, 18-29, doi:10.2507/IJSIMM17(1)407

[27] Denkena, B.; Dahlmann, D.; Kiesner, J. (2014). Sensor integration for a hydraulic clamping system, Procedia Technology, Vol. 15, 465-473, doi:10.1016/j.protcy.2014.09.006

[28] Gameros, A.; Lowth, S.; Axinte, D.; Nagy-Sochacki, A.; Craig, O.; Siller, H. R. (2017). State-ofthe-art in fixture systems for the manufacture and assembly of rigid components: A review, International Journal of Machine Tools and Manufacture, Vol. 123, 1-21, doi:10.1016/ j.ijmachtools.2017.07.004

[29] Lee, J.; Bagheri, B.; Kao, H.-A. (2015). A cyber-physical systems architecture for industry 4.0based manufacturing systems, Manufacturing Letters, Vol. 3, 18-23, doi.10.1016/ j.mfglet.2014.12.001

[30] Wang, L.; Wang, X. V. (2018). Outlook of cloud, CPS and IoT in manufacturing, Wang, L.; Wang, X. V. (Eds.), Cloud-Based Cyber-Physical Systems in Manufacturing, Springer, Cham, 377-398, doi:10.1007/978-3-319-67693-7_15

[31] Li, B.; Melkote, S. N. (2001). Fixture clamping force optimisation and its impact on workpiece location accuracy, The International Journal of Advanced Manufacturing Technology, Vol. 17, No. 2, 104-113, doi: $10.1007 / \mathrm{s} 001700170198$

[32] Deiab, I. M.; Elbestawi, M. A. (2005). Experimental determination of the friction coefficient on the workpiece-fixture contact surface in workholding applications, International Journal of Machine Tools and Manufacture, Vol. 45, No. 6, 705-712, doi:10.1016/ j.ijmachtools.2004.09.021 